\title{
Clasificación Histopatológica de Linfomas Caninos en la Casuística del Laboratorio de Patología Veterinaria de la Universidad Nacional Mayor de San Marcos (1996-2012)
}

\author{
Histopathological Classification of Canine Lymphomas in the Casuistry of the \\ Veterinary Pathology Laboratory of University of San Marcos (1996-2012)
}

Víctor Puicón N. ${ }^{1,3}$, Nieves Sandoval C. ${ }^{1}$, Danilo Gouveia W. ${ }^{2}$

\section{RESUMEN}

\begin{abstract}
El presente estudio tuvo como objetivo emplear los criterios de la Organización Mundial de la Salud (OMS) en la clasificación histopatológica del linfoma canino en los casos diagnosticados en el laboratorio de patología veterinaria de la Universidad Nacional Mayor de San Marcos, Lima, Perú, entre 1996 y 2012. Se revisaron 1778 informes con diagnóstico histopatológico de neoplasias caninas y se encontraron 16 casos con diagnóstico histopatológico de linfoma canino. Se identificaron los siguientes tipos de linfomas: linfoma difuso de células grandes B (7/16) (subtipo inmunoblástico [4/16], subtipo centroblástico [2/16], subtipo rico en células T [1/16]), linfoma de células del manto (3/16), linfoma T periférico inespecífico (2/16), linfoma linfoblástico de células precursoras B/T (2/16), linfoma anaplásico de células grandes (1/16) y micosis fungoides $(1 / 16)$.
\end{abstract}

Palabras clave: linfoma, neoplasia, clasificación, canino

\section{Abstract}

The aim of this study was to apply the criteria of the World Health Organization (WHO) in the histopathological classification of canine lymphoma on cases diagnosed from 1996 to 2012 at the veterinary pathology laboratory of San Marcos University, Lima, Peru. A total of 1778 reports of canine neoplasia were revised and 16 cases with

\footnotetext{
${ }^{1}$ Laboratorio de Histología, Embriología y Patología Veterinaria, Facultad de Medicina Veterinaria, Universidad Nacional Mayor de San Marcos, Lima, Perú

${ }^{2}$ Histopet - Laboratorio de Patología Veterinaria, São Paulo/SP, Brasil

${ }^{3}$ E-mail: victor_puicon_1704@hotmail.com
}

Recibido: 9 de agosto de 2013

Aceptado para publicación: 25 de marzo de 2014 
histopathological diagnoses of canine lymphoma were studied. The following types of lymphoma were identified: diffuse large B cell lymphoma (7/16) (immunoblastic subtype [4/16], centroblastic subtype [2/16], rich subtype T cells [1/16]), mantle cell lymphoma (3/ 16), peripheral T-cell lymphoma not otherwise specified (2/16), precursor B/T lymphoblastic lymphoma (2/16), anaplastic large cell lymphoma (1/16) and mycosis fungoides (1/16).

Key words: lymphoma, neoplasia, classification, canine

\section{INTRODUCCIÓN}

El linfoma canino es una neoplasia hematopoyética que abarca diversos tipos histológicos, con un comportamiento biológico definido por la morfología celular y las características tisulares (McGavin y Zachary, 2007; Valli et al., 2011). Se define como una proliferación de células linfoides malignas que surgen de linfonódulos u órganos viscerales sólidos, como el hígado o bazo (Romani et al., 2004). Se le considera como una enfermedad severa, progresiva y fatal (Couto, 1985). Esta neoplasia se presenta en caninos, mayormente entre los 6 a 12 años de edad, sin diferencias entre sexos (Vail y Ogilvie, 2003); asimismo, constituye entre el 7 y $24 \%$ de las neoplasias en caninos (Gear, 2009 ) y el $83 \%$ de todas las neoplasias malignas hematopoyéticas, siendo la más común de las alteraciones linfoproliferativas en pequeños animales (Vail y Ogilvie, 2003).

La clasificación del linfoma se basa en la localización anatómica y de criterios histológicos (Couto, 2001). La clasificación de linfomas de la Organización Mundial de la Salud, adaptada por Valli et al. (2002) diferencia los tipos de linfoma por diversos criterios, entre estos, las características tisulares y celulares de la población linfoide atípica.

Los signos clínicos de la forma multicéntrica del linfoma canino, forma anatómica más común de la enfermedad, se manifiestan primeramente como linfoadenopatías en zonas donde se desarrolla la lesión inicial. El diagnóstico de linfoma maligno se realiza por histopatología y citología, siendo el uso de la inmunohistoquímica un requisito fundamental para los casos donde no se puede alcanzar una caracterización histológica (Guija de Arespacochaga et al., 2007) y el diagnóstico se complica debido a que las células pierden su diferenciación celular, adquiriendo una variación morfológica y un comportamiento biológico distinto a su estirpe original.

Los métodos inmunnohistoquímicos no se encuentran disponibles en los centros de diagnóstico del país, deallí que se hace necesaria la aplicación de los criterios histopatológicos basados en un sistema estandarizado de clasificación, con la finalidad de establecer un diagnóstico más preciso del tipo histológico, y de esa forma poder aplicar el tratamiento específico y estimar el pronóstico adecuado. Sin embargo, tampoco se dispone de estudios sobre criterios histológicos para la clasificación del linfoma canino, de allí que el presente estudio enfoca la caracterización histopatológica de linfomas caninos diagnosticados en el Laboratorio de $\mathrm{Pa}$ tología de la Facultad de Medicina Veterinaria, Universidad Nacional Mayor de San Marcos, entre 1996 y 2012.

\section{Materiales y Métodos}

Se revisaron 1778 informes con diagnóstico histopatológico de neoplasias caninas del Laboratorio de Patología de la Facultad de Medicina Veterinaria, Universidad Nacional Mayor de San Marcos, dentro del periodo 1996 a 2012. De estos, 49 presentaban 
diagnóstico de linfoma canino mediante histopatología y 130 con diagnóstico de linfoma canino mediante citología. Se buscaron las láminas histopatológicas de los 49 casos encontrándose que solo 16 de ellas se encontraban aptas para la clasificación histopatológica, en tanto que las 33 restantes estaban deterioradas o no pudieron ser ubicadas.

La clasificación histopatológica se realizó siguiendo los criterios establecidos por la Organización Mundial de la Salud y adaptada por Valli et al. (2002). Las láminas se observaron mediante un microscopio óptico con aumento de 100x para evaluar el patrón (nodular o difuso), integridad de la cápsula del parénquima e infiltración de tejidos adyacentes. Asimismo, se evaluó el tamaño del núcleo celular en relación al tamaño de glóbulos rojos (GR) (pequeño: 1 a 1.25 GR; intermedio: >1.25 a 2 GR; grande: >2 GR), características celulares (citoplasmáticas, nucleares y patrón de cromatina), índice mitótico (contaje de células en división mitótica por campo), y características tisulares indicativas de posibles tipos de linfoma, con aumentos de 400x y 1000x.

Todas estas características fueron comparadas por tres especialistas con la clasificación histológica de linfomas caninos (nodulares y difusos) descritas por Valli y Caswell (2002) (Ver cuadros 1 y 2). Uno de los evaluadores fue un patólogo especialista en neoplasias hemolinfáticas y los otros dos eran veterinarios patólogos.

\section{Resultados}

De los doce tipos de linfoma canino descritos histológicamente y adaptados por Valli et al. (2002), se pudo describir a seis de ellos (Figs. 1 y 2):

- $\quad$ Linfoma difuso de células grandes B (7/16)

- $\quad$ Linfoma de células del Manto (3/16)

- Linfoma linfoblástico de células precursoras $\mathrm{B} / \mathrm{T}(2 / 16)$
- $\quad$ Linfoma T periférico inespecífico (2/16)

- Linfoma anaplásico de células grandes $(1 / 16)$

- $\quad$ Micosis fungoides (1/16)

El linfoma difuso de células grandes B fue el tipo de mayor presentación, lográndose determinar tres subtipos (inmunoblástico, centroblástico y rico en células $\mathrm{T}$ ).

El linfoma difuso de células grandes B inmunoblástico (4 casos, Fig. 1A) presenta un patrón difuso, células con citoplasma variable, presencia de nucléolo central y prominente, patrón de cromatina definida, y tamaño celular dos veces mayor que el diámetro de un glóbulo rojo. El linfoma difuso de células grande B centroblástico (2 casos, Fig. 1B) presenta un patrón difuso, con células de citoplasma escaso a moderado, tamaño celular de dos veces mayor que el diámetro de un glóbulo rojo y, a diferencia del anterior, presenta varios nucléolos rodeando la membrana nuclear. El linfoma difuso de células grandes B rico en células T (1 caso, Fig. 1C) presenta un patrón difuso, con una mezcla de linfocitos pequeños maduros con cromatina dispersa rodeando a células grandes, núcleos vesiculares, nucléolo prominente, tamaño celular dos veces mayor que el diámetro de un glóbulo rojo y de citoplasma escaso a moderado en volumen.

En el linfoma de células del manto se observan áreas multifocales de proliferación linfoide de la zona del manto coalescentes y que surgen de una arteriola central (Fig. 1D). Se observan linfocitos neoplásicos de tamaño intermedio (1.2-2.0 en relación al diámetro de un glóbulo rojo), redondos a ovalados, escaso citoplasma, muchos con nucléolo ausente o pequeño (Fig. 1E).

El linfoma linfoblástico de células precursoras $\mathrm{B} / \mathrm{T}$ presenta linfocitos neoplásicos de tamaño celular de 1.0-1.25 en relación al diámetro de un glóbulo rojo, escaso citoplasma, membranas nucleares delicadas pero definidas, patrón de cromatina dispersa. Algunas células con nucléolos pequeños (Fig. 1F). 


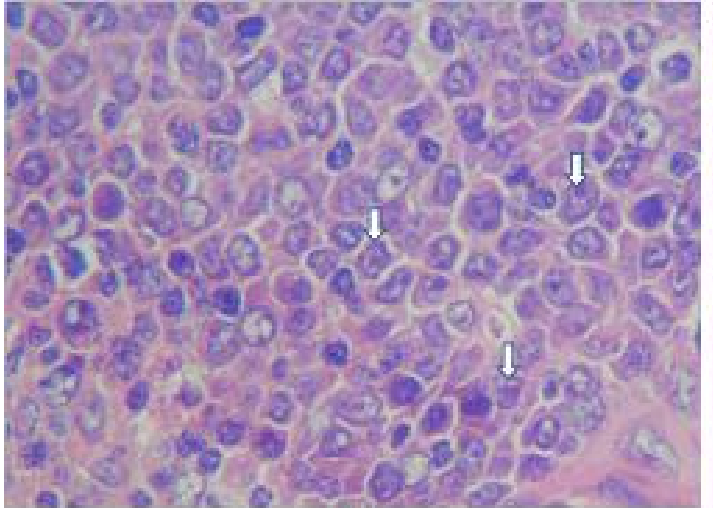

(A)

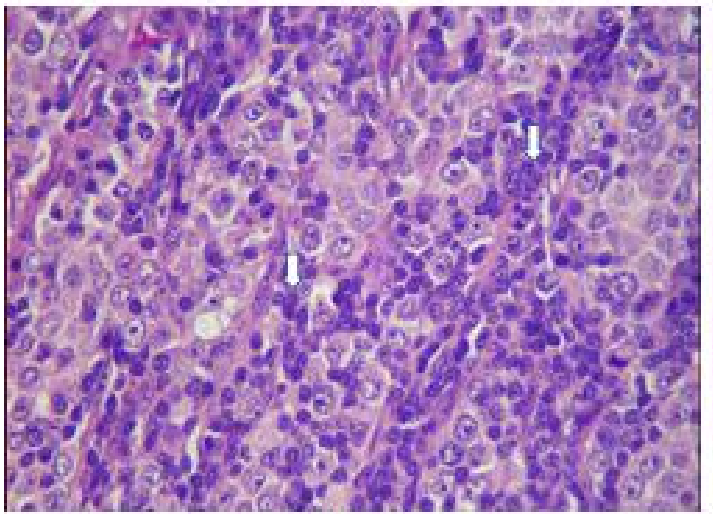

(C)

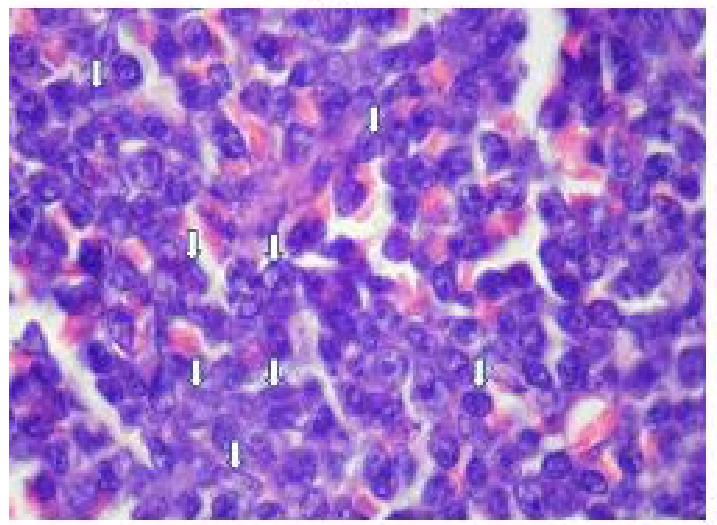

(E)

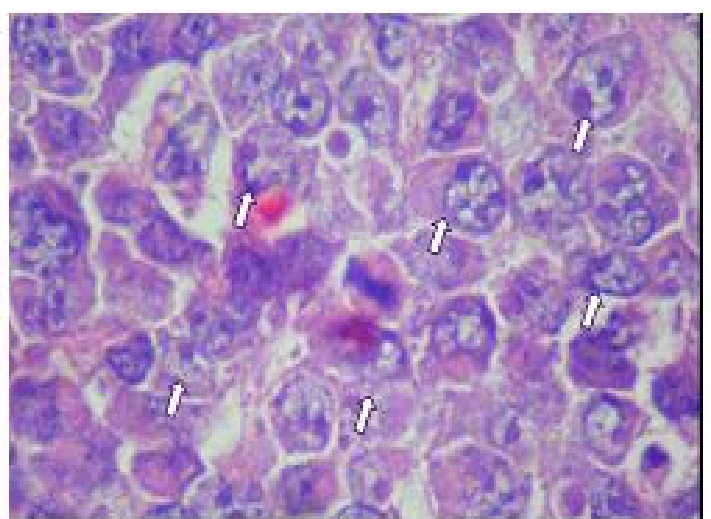

(B)

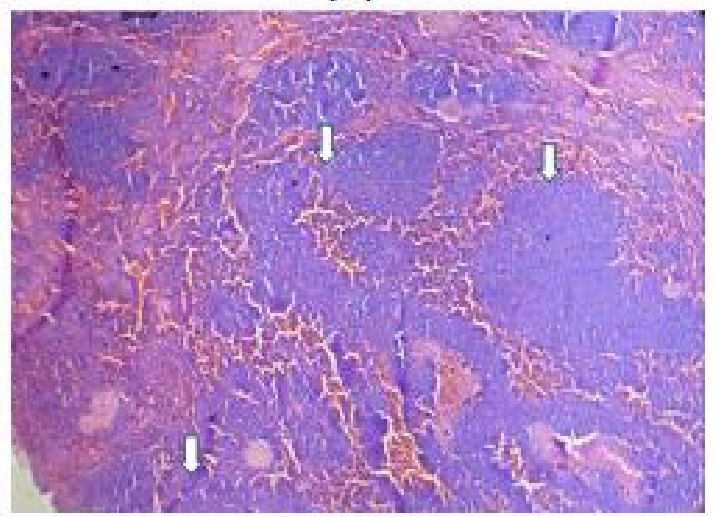

(D)

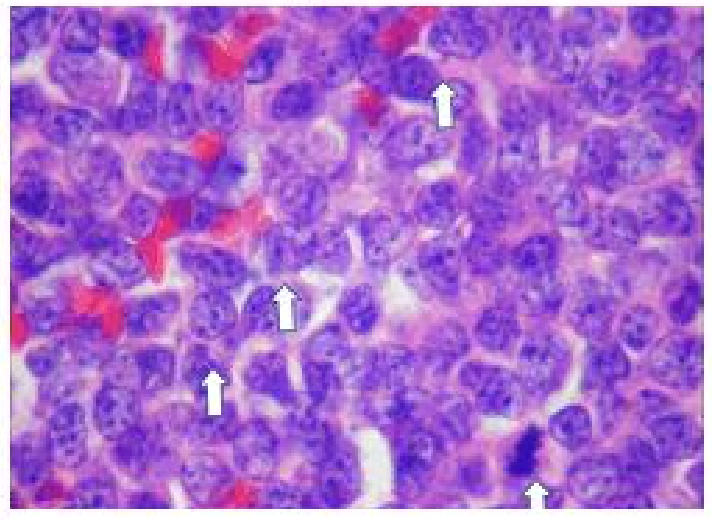

(F)

Figura 1. (A) Macho cruzado macho, 9 años, linfonódulo submandibular. Linfoma difuso de células grandes B subtipo inmunoblástico. Presencia de nucléolo prominente (flechas), Índice mitótico (IM): 5.5 mitosis (mit)/400x; (B) A nivel de linfonódulo. I.M: 6 mit/ 400x. Presencia de 2 a 3 nucléolos rodeando la membrana nuclear (flechas); (C) Schnauzer macho, 6 años, linfonódulo submandibular. Linfocitos pequeños maduros (flechas). IM: 5.5 mit/400x; (D) Macho, 4 años, en bazo. IM nulo. Proliferación linfoide de la zona del manto coalescentes y que surgen de una arteriola central; (E) Macho cruzado, 4 años, en bazo. Linfocitos de tamaño intermedio, escaso citoplasma y de nucléolos ausentes que provienen de la zona del manto (flechas); (F) Schnauzer, en hígado. Linfocitos de membrana nuclear definida y cromatina dispersa (flechas). I.M: $9.5 \mathrm{mit} / 400 \mathrm{x}$. La flecha inferior derecha indica una mitosis en metafase. H-E, 400x 


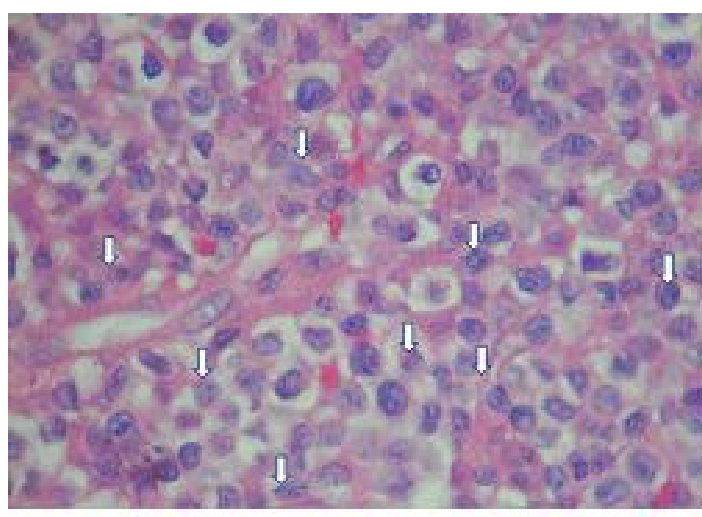

(A)

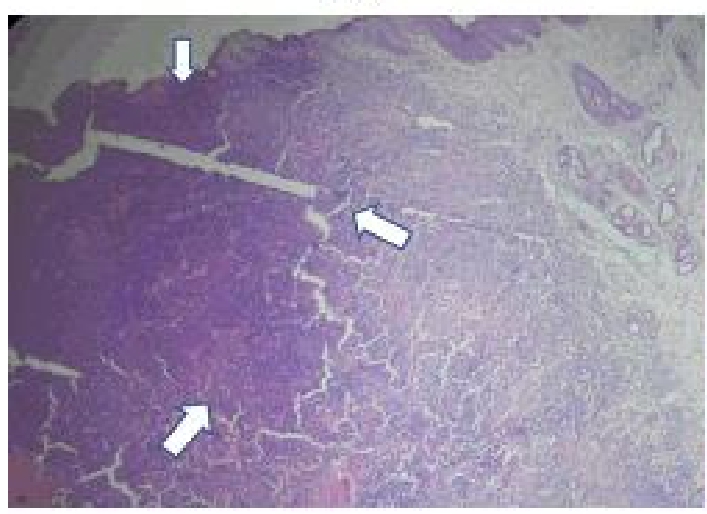

(C)

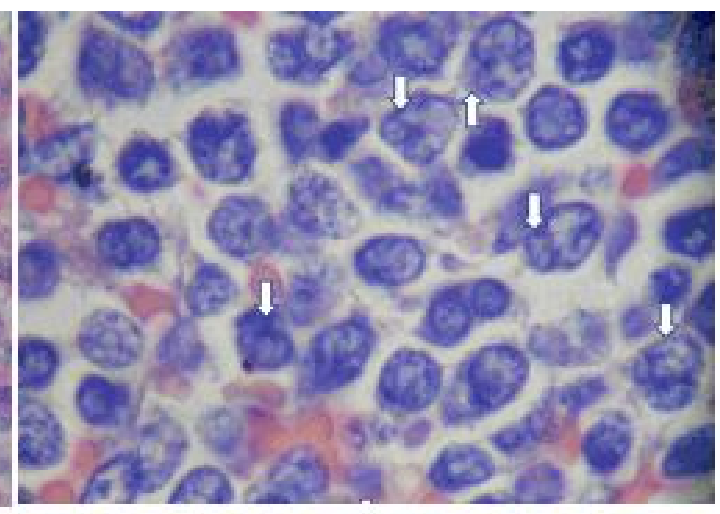

(B)

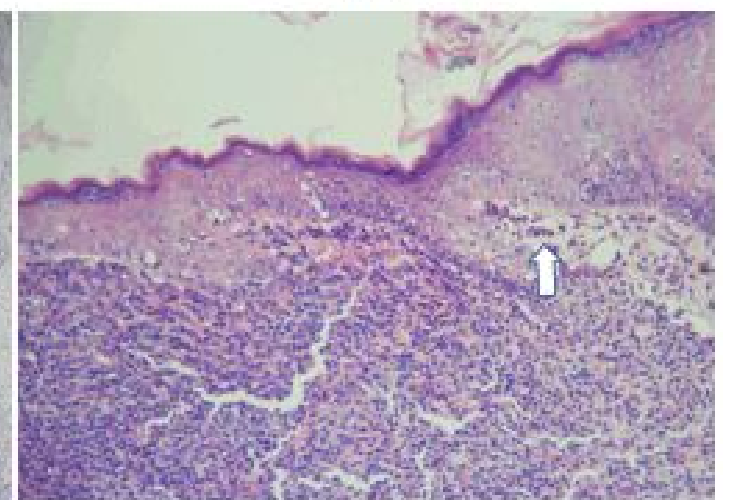

(D)

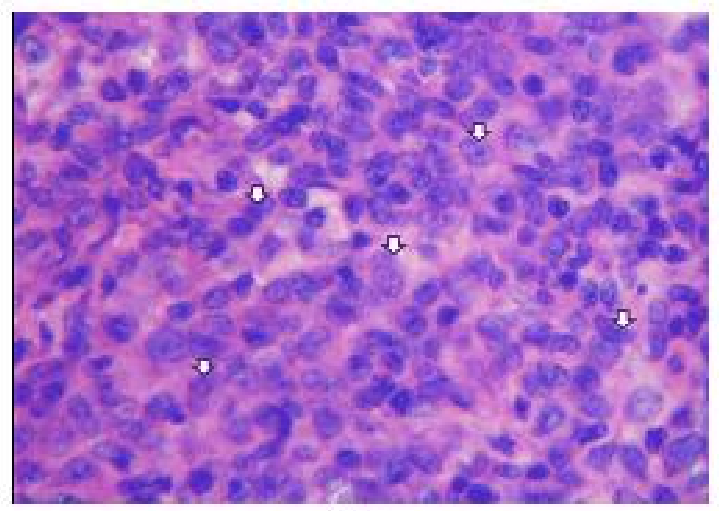

(E)

Figura 2. (A) Bóxer macho, mucosa labial. Linfocitos con núcleos de distintas formas y tamaños (flechas). Índice mitótico (IM): 5.5 mitosis (mit)/400x, H-E, 400x; (B) Bóxer macho, 8 años, linfonódulo submandibular. Células Hallmarks (flechas), IM 3 mit/ 400x, H-E, 1000x; (C) Pinscher hembra, piel. Proliferación linfoide invasiva en epidermis (flechas), H-E, 100x; (D) Pinscher hembra, piel. Proliferación linfoide rodeadas de un halo claro en la unión epidemo-dermal (flecha), IM: 3.5 mit/400x, H-E, 400x; (E) Pinscher hembra, piel. Células cerebriformes (flechas), H-E, 1000x 
El linfoma $\mathrm{T}$ periférico inespecífico en piel de tipo no epiteliotrópico presenta células linfocíticas de citoplasma moderado a abundante, márgenes celulares definidos, núcleos de distintos tamaños y formas (poiquilocariosis), y presencia de nucléolos de forma variable a nivel de la dermis (Fig. 2A).

El linfoma anaplásico de células grandes presenta células con citoplasma espumoso, tamaño celular 2 veces mayor que el diámetro de un glóbulo rojo, núcleos reniformes y elongados (células denominadas «hallmarks cells»), además de presencia de células binucleadas (Fig. 2B).

La micosis fungoides presenta una proliferación neoplásica que invade agresivamente la epidermis (Fig. 2C), pudiendo estar rodeadas de un halo claro en la unión epidemodermal (Fig. 2D). A un mayor aumento se observan células de citoplasma moderado acidófilo, tamaño celular de 1.0-1.25 en relación al diámetro de un glóbulo rojo, membranas nucleares delicadas pero bien definidas, patrón de cromatina dispersa y hendiduras nucleares poco pronunciadas que las definen como cerebriformes (Fig. 2E).

\section{Discusión}

El diagnóstico histopatológico tiene muchas ventajas con respecto al diagnóstico citológico, ya que características tisulares como patrón, invasión de tejidos adyacentes e infiltración neoplásica a nivel capsular son evaluadas en la histopatología (Valli, 2007); además, para los casos de linfomas indolentes, como el linfoma de células del Manto, el linfoma de la zona $\mathrm{T}$ y el linfoma de la Zona Marginal, la citología solo revela una población uniforme de linfocitos pequeños y el diagnóstico los puede considerar como procesos benignos (Valli, 2007).

Las clasificaciones de los linfomas han sido diversas y han ido evolucionando en los últimos años. La mayoría de los esquemas han sido adaptados desde el linfoma humano
(Parodi, 2001). La Organización Mundial de la Salud (OMS) separa los linfomas desde su origen celular como célula precursora o célula madura y define cada tipo según características clínicas, morfológicas, inmunofenotípicas y genéticas obteniendo como ventaja la caracterización de los linfomas extraganglionares, distinguiendo cada entidad histopatológica según la diferenciación, tamaño celular y la agresividad en relación con el pronóstico. Este sistema de clasificación se diferencia de otras clasificaciones como la de Kiel y Working Formulation, que consideran únicamente los criterios morfológicos, como el crecimiento dentro del linfonódulo (nodular o difuso), y el tamaño de las células neoplásicas (pequeñas, grandes o mixtas) (Parodi, 2001). Además, Valli et al. (2011) demostraron que la aplicación de la clasificación histológica de la OMS es un sistema práctico para patólogos veterinarios no especialistas en hematopatología.

En la diferenciación del tipo $\mathrm{T}$ y $\mathrm{B}$, Vezzali et al. (2009) indican que, como regla general, los linfomas de células B muestran histológicamente un menor pleomorfismo que los linfomas de células $\mathrm{T}$ (a excepción del linfoma linfoblástico de células precursoras $\mathrm{T}$ ), además de estar asociados con neoangiogénesis e inflamación (Vezzali et al., 2009). En cuanto al pronóstico de supervivencia, los últimos estudios de importancia histopatológica determinaron que perros que padecían linfomas con un índice mitótico mayor de 20 mitosis/400x sobrevivían 33 días, mientras aquellos con índice mitótico menor de 20 mitosis/400x sobrevivían 188 días en promedio (Valli et al., 2013). En el país, esta enfermedad se suele diagnosticar únicamente como «linfoma», basado en el diagnóstico citológico.

Valli et al. (2013), basados en la clasificación de la OMS, clasificaron 992 casos de linfoma encontrando las siguientes frecuencias: linfoma difuso de células grandes B (39.3\%), linfoma de la zona marginal (6.5\%), linfoma $\mathrm{T}$ periférico inespecífico $(13.6 \%)$, linfoma de la zona $\mathrm{T}(11.2 \%)$, linfoma 
linfoblástico de células precursoras $\mathrm{B} / \mathrm{T}$ (4.8\%), linfoma de células del Manto (1.6\%) y linfoma folicular $(0.3 \%)$, haciendo un total de siete tipos de linfomas; en tanto que en el presente estudio se logró clasificar seis tipos histológicos de 12 tipos de linfomas estandarizados.

En el presente estudio, las 16 láminas de 179 casos de linfomas revelan que los diagnósticos de esta neoplasia en el canino se han venido basando en el diagnóstico citológico, optándose por el tratamiento clásico sin evidencia del tipo celular comprometido. Los resultados están apoyados en un pequeño número de casos, por lo que es necesario convalidarlos con un mayor tamaño muestral.

La quimioterapia ha sido la terapéutica más utilizada para los linfomas (Valli et al., 2011). Estos esquemas se basan, usualmente, en la aplicación de agentes paliativos como la doxorrubicina, L-asparaginasa, vincristina, ciclofosfamida, clorambustilo y prednisona. Sin embargo, estudios más recientes (Valli et $a l ., 2013)$ han demostrado que el linfoma se debe tratar de acuerdo a determinadas características histológicas como la morfología e índice mitótico (Valli et al., 2006), que permite predecir el tiempo de supervivencia y la respuesta al tratamiento empleado. Es necesaria la selección de protocolos específicos de los tipos individuales de linfoma con el objetivo terapéutico más cercano al tratamiento curativo, y la adaptación probable de tratamientos de uso en medicina humana, debido a que estudios genéticos en mamíferos indican que los mismos tipos de linfoma en humano y en el canino responden a un similar tipo de terapia (Moore et al., 1995).

\section{Conclusiones}

- La clasificación histopatológica de los tipos de linfoma canino, según los criterios de la Organización Mundial de la Salud, permitieron determinar la ocurrencia de seis tipos en la casuística del la- boratorio de patología de la FMVUNMSM. El linfoma difuso de células grandes B (subtipos inmunoblástico, centroblástico y rico en células $\mathrm{T}$ ), linfoma de células del manto, linfoma linfoblástico de células precursoras $\mathrm{B} / \mathrm{T}$, linfoma anaplásico de células grandes, linfoma $\mathrm{T}$ periférico inespecífico y micosis fungoides.

- El linfoma difuso de células grandes B fue el tipo más frecuente (7/16), siendo el subtipo inmunoblástico el de mayor presentación (4/16).

\section{Literatura Citada}

1. Couto C. 1985. Canine lymphomas: something new, something old. Comp Cont Educ Pract 7: 291-302.

2. Couto C. 2001. Linfoma no cão e no gato. En: Nelson R, Couto C (eds). Medicina interna de pequenos animais. $2^{\mathrm{a}}$ ed. Rio de Janeiro: Guanabara. p 882-889.

3. Gear R. 2009. Practical update on canine lymphoma. Classification and diagnosis. In Practice 31: 380-384. doi:10.1136/inpract.31.8.380

4. Guija de Arespacochaga A, Schwendenwein I, Weissenboeck $H$. 2007. Retrospective study of 82 cases of canine lymphoma in Austria based on the Working Formulation and immunophenotyping. J Comp Pathol 136: 186-192.

5. McGavin D, Zachary J. 2007. Pathologic basis of veterinary disease. $4^{\text {th }}$ ed. USA: Mosby. $1476 \mathrm{p}$.

6. Moore A, Leveille C, Reimann $K$. 1995. The expression of P-glycoprotein in canine lymphoma and its association with multidrug resistance. Cancer Invest 13:475-447.

7. Parodi A. 2001. Classification of malignant lymphoma in domestic animals: history and conceptual evolution. Eur J Vet Pathol 7(2): 43-47.

8. Romani A, Sant'ana F, Rabelo R, Moura M, Silva C. 2005. Linfossarcoma multicêntrico em um cão relato de caso. Ciênc Anim Bras 5: 223-225. 
9. Vail D, Ogilvie G. 2003. Neoplasias linfóides. En: Birchard SJ, Sherding RG (eds). Manual Saunders. Clínica de pequenos animais. $2^{\mathrm{a}}$ ed. São Paulo: Roca. p 227-236.

10. Valli V. 2007. Veterinary comparative hematopathology. $5^{\text {th }}$ ed. USA: Blackwell Publishing. $558 \mathrm{p}$.

11. Valli V, Caswell J, Jacobs R, Parodi A. 2002. Histological classification of hematopoietic tumors of domestic animals. Washington: Armed Forces Institute of Pathology and the World Health Oganization. $190 \mathrm{p}$.

12. Valli V, San Myint M, Barthel A, Bienzle D, Caswell J, Colbatzky F, Durham A, et al. 2011. Classification of canine malignant lymphomas according to the World Health Organization criteria. Vet Pathol 48: 198-211.doi: 10.1177/0300985810379428

13. Valli V, Kass P, San Myint M, Scott F. 2013. Canine lymphomas: association of classification type, disease stage, tumor subtype, mitotic rate, and treatment with survival. Vet Pathol 50: 738-748. doi: 10.1177/0300985813478210

14. Valli V, Vernau W, De Lorimier L, Graham P, Moore P. 2006. Canine indolent nodular lymphoma. Vet Pathol 43: 241-256.

15. Vezzali E, Parodi A, Marcato P. 2009. Histopathologic classification of $171 \mathrm{ca}-$ ses of canine and feline non-Hodgkin lymphoma accoing to the WHO. Vet Comp Oncol 8: 38-49. doi: 10.1111/j.14765829.2009.00201.x 